\title{
On the Effects of Federal Capital Taxation on Growing and Declining Areas
}

\author{
Paul N. Courant ${ }^{1}$ \\ Department of Economics, and Institute of Public Poltcy Studies, The University of \\ Michigan, Ann Arbor, Michigan $4810^{9}$
}

Received April 26, 1982

\begin{abstract}
It has often been claimed that measures designed to stimulate capital formation at the national level will accelerate the decline of regions that are not growing. A number of simple models are employed to evaluate this claim, and it is found that the effect of national subsidies is ambiguous. Further, it is shown that on average the form of capital stimulus used in the Economic Recovery Tax Act of 1981 will tend to help higher-tax regions, which tend to be those that have experienced relative economic declines in recent years.
\end{abstract}

\section{INTRODUCTION}

The migration of capital and labor from the "old" north to the "new" south and west has become an issue in the making of federal tax policy. Both of the last two major federal tax revisions (1978 and 1981) have been influenced by a concern that general measures designed to stimulate capital formation would have differential interregional and intraregional impacts - that they would help the new regions and hurt the old, and help the suburbs while hurting the central cities. A proposal to extend the investment tax credit to structures was removed from the 1978 tax bill for the explicit reason that such a provision in the tax law would put older central cities at an economic disadvantage. In the 1981 law, one of the ornaments on the Christmas tree was a large investment tax credit for rehabilitation of structures 30 years old and older; the purpose of this provision was to compensate older urban areas for the negative impact that stimuli to new investment were perceived to have on them.

In the context of a system of capital taxation that is as much an amalgam of special provisions as a code following from any coherent definition of the proper tax base, it is not surprising that cities and regions can lobby for

'I am grateful to Ted Bergstrom and Michael Wolkoff for valuable discussions of the topics considered here. William Oakland, Bruce Hamilton, Peter Mieszkowski, and John Yinger made valuable comments on an earlier draft. 
special treatment and achieve some measure of success. After all, it seems to be a given of federal tax policy that everyone is allowed some special treatment. $^{2}$ What is more surprising is that there seems to be general agreement on the proposition that measures designed to stimulate capital formation nationwide will have the effect of damaging the economic condition of areas that are not growing while accelerating growth in areas that are growing. ${ }^{3}$ This proposition is by no means self-evident, and indeed the models that will be presented later in this paper indicate that the proposition is in many ways untrue.

The issue is an important one. If general measures designed to promote investment have distributional consequences that adversely affect identifiable regions, then there is a genuine equity-efficiency tradeoff that should at least be considered in making policy. ${ }^{4}$ If, on the other hand, it is found that the differential effects of investment stimuli are nonexistent or small, programs designed to increase the rate of investment nationally can be designed without taking such matters into consideration. This, in turn, should lead to a more efficient allocation of the capital stock. ${ }^{5}$

The next section of this paper presents a number of simple models that are designed to permit investigation of the effect of national investment stimuli on growing and declining areas. The most plausible of these models implies that national investment stimuli will increase the rate of capital outflow from declining regions and increase the equilibrium level of output in both declining regions and growing regions. At worst, then, such stimuli can be characterized as a mixed curse from the perspective of the declining areas.

In the following section of the paper, it is argued that because of the interaction between federal and state and local tax rules, areas with higher state and local corporate tax rates are differentially favored by federal

\footnotetext{
${ }^{2}$ Herbert Stein once made the observation that you can't subsidize everybody all of the time. He might have added "but you can try."

${ }^{3}$ See, for example, Peterson [17], Peterson and Mueller [18], Vaughan [27], and Northeast-Midwest Coalition [16]. Peterson states: "Any tax incentive that differentially favors investment in new capital facilities will tend to accelerate adjustment of the capital stock to new locational incentives" $[17$, p. 6].

${ }^{4}$ The issue of whether the rate of capital formation in recent years has been suboptimal in some sense is beyond the scope of this paper. Regardless of the merits of current national policy, it is certainly conccivable that it would be in the national interest to stimulatc capital formation and it is thus important to be able to evaluate the urban and regional consequences of measures that are designed to effect the stimulus.

${ }^{5}$ The removal of the 1978 proposal to extend the investment tax credit to structures is a striking example of a case where concern with the urban impact of a national tax proposal had an unambiguously negative impact on economic efficiency. As has been noted by Bradford [2], and many others, a neutral investment tax credit (neutral in the sense that the social rate of return to all physical capital would be equal) would require a higher rate for structures than for equipment. Equalizing the credit rates would have at least been a step in the right direction.
} 
accelerated depreciation provisions. Furthermore, it is argued that corporate income taxes at any level of government are, for a wide range of parameter values (including those currently obtaining), net subsidies to capital formation. To the extent that declining regions have higher tax rates than growing regions, then, they have higher investment subsidies, leading to a larger capital stock than would otherwise obtain.

\section{AGGREGATE MODELS}

In order to investigate the effect of investment stimuli on growing and declining regions, it is necessary to develop a model that is consistent with the fact that some areas are growing while others are declining, and that the processes of growth and decline are not instantaneous. A natural way to go about constructing such a model is to borrow from the growth theorists (following a long tradition in urban economics), and treat capital in different locations the way putty-clay growth models treat capital of different vintages. ${ }^{6}$

\section{II.A. A Fixed Coefficient Model}

Consider an economy that produces a homogeneous good by means of a production process that uses capital $(K)$ and labor $(N)$ in fixed proportions. (Units of capital and labor are defined so that they are used in equal quantities.) Production is homogeneous of degree one and takes place at two locations: location 1 (called "old") and location 2 (called "new"). The economy's labor force is fixed at $\bar{N}$, the rental cost of capital is equal to the world interest rate $(r){ }^{7}$ and the price of the consumption good is normalized at unity. There is perfect competition in all markets. Labor is perfectly mobile, physical capital declines at a constant rate $\delta$, and output per unit of labor in each location is denoted by $\alpha_{i}$.

Assume that at some time $t \alpha_{1}=\alpha_{2}$ and that production takes place at both locations. ${ }^{8}$ The competitive requirement that there be zero profits

\footnotetext{
${ }^{6}$ See Solow [20] for an introduction to the literature.

${ }^{7}$ Throughout this section of the paper I assume that $r$, the net interest rate received by savers, is fixed in a world capital market. This assumption provides the maximum possible scope for investment stimuli. The opposite polar assumption, that the supply of investment funds is perfectly inelastic, would assure that any investment subsidy would have no net effect. An intermediate assumption, that the interest rate responds positively to investment demand, could be incorporated into the models by adding a saving function in which savings are increasing in the interest rate. This addition, while very important for predicting the effect of investment subsidies on the capital stock, is simply an unnecessary complication in the context of models designed to illuminate the effect of investment subsidies on inter-locational flows of resources.

${ }^{8}$ Obviously, in a model such as this one production will take place in more than one location only by historical accident. There is nothing to favor producing in one place rather than another.
} 
requires that

$$
r K_{i}+w N_{i}=Q_{i} \quad\left(i=1,2,3 ; r K_{i}<Q_{i}\right),
$$

where $w$ is the wage, $Q_{i}$ is total output, and location 3 is the entire economy. Note that as long as $Q_{i}>r N_{i}$ (recalling that $N_{i}=K_{i}$ ), everything in the model is determined by the exogenously given levels of $r$ and $\bar{N}$ and the arbitrary distribution of population between locations. The wage is determined as a residual, and is a pure rent. ${ }^{9}$ The dynamics of the model are trivial. Capital wears out at rate $\delta$ and is replaced at the same rate.

Now suppose that for some reason the value of $\alpha_{1}$ falls below that of $\alpha_{2}{ }^{10}$ Clearly, the new equilibrium will have all production taking place at location 2, with $Q_{3}$ unchanged. Adjustment to the new equilibrium will take place in one of two ways. If the new value of $\alpha_{1}$ is still greater than $w$, then the new equilibrium will be approached asymptotically; as capital wears out in location 1, it will be replaced in location 2. If the new value of $\alpha_{1}$ is less than $w$, it will not be profitable to man the existing capital stock in location 1 , and location 1 will be abandoned immediately. In either case, the wage will be unchanged, because the wage must be consistent with zero profits being earned in location 2, and technology and prices in location 2 are unchanged. ${ }^{11}$ In the continuous adjustment case, the reduction in output in location 1 is absorbed entirely by owners of existing capital in location 1 , and output approaches the equilibrium level as capital in location 1 wears out and both capital and labor employed in location 2 increase.

The model is illustrated in Fig. 1. $N_{1}$ is measured from left to right, while $N_{2}=\bar{N}-N_{1}$ is measured from right to left. $N^{*}$ shows the initial (arbitrary) division of population. Output per head in each location is measured on the $y$ axis. Perfect competition requires that in any location where investment takes place, the wage is just equal to $\alpha_{i}-r$. Total output in each location is

\footnotetext{
${ }^{9}$ If $Q_{3}<r N_{3}$, no production takes place.

${ }^{10}$ Throughout this paper, the impetus for a flow of resources from old locations to new ones will be modelled as a reduction in the productivity of resources employed in the old locations. What I have in mind here is a flow caused by some combination of increased energy prices and possible inefficiencies that arise when new equipment is used in old structures. To the extent that resource flows are caused by improvements in productivity in new places, rather than reductions in old places, the implications for the way in which the flows occur will be qualitatively unchanged, although the effects on total output for the economy as a whole will be different. (For example, a reduction in the productivity of mobile factors in one location cannot by itself lead to an increase in GNP; an increase in the productivity of such factors in some location cannot by itself lead to a reduction in GNP.)

${ }^{11}$ The price of output is assumed fixed. This assumption can be justified either by assuming a world price of the consumption good or by recognizing that all accounting in the model can be done using physical output as the accounting unit.
} 


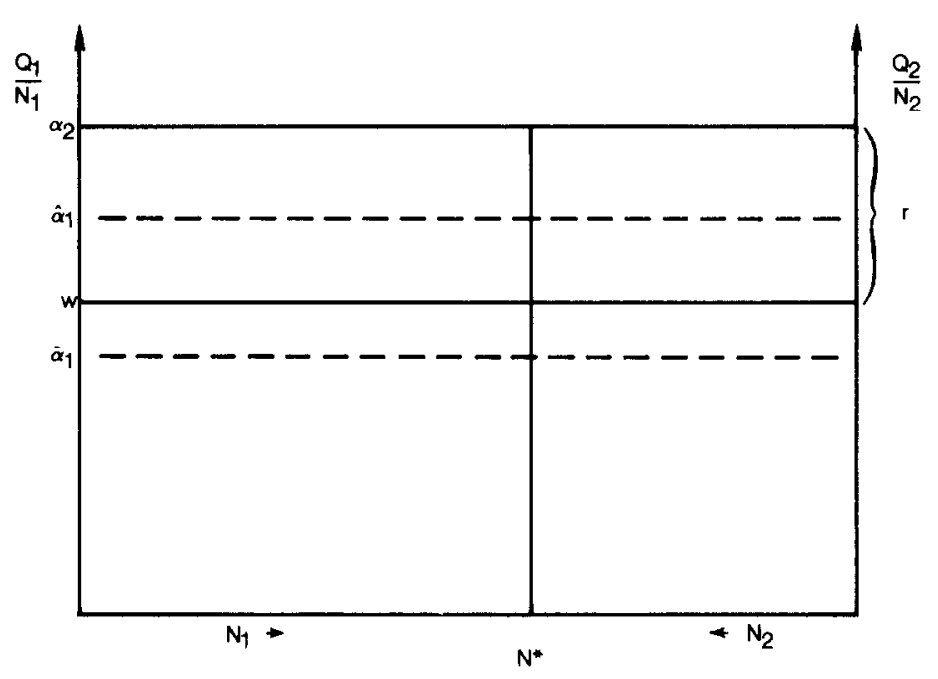

Figure 1

simply the area under the output per head line. Before the "shock" (i.e., when $\alpha_{1}=\alpha_{2}$ ), total output is simply $\alpha_{2} \bar{N}$. After the shock, if $\alpha_{1}$ falls to a level greater than $w$ (such as $\hat{\alpha}_{1}$ ), output falls (initially by $\left(\alpha_{2}-\hat{\alpha}_{1}\right) N^{*}$ ), and then rises slowly as capital depreciates in location 1 and the capital stock grows in location 2 . The wage is unchanged. If $\alpha_{1}$ falls below $w$ (e.g., to $\hat{\alpha}_{1}$ ) then all employment will immediately flow to location 2 , and location 1 will be abandoned.

The effect of capital subsidies in this model is transparent. The subsidy reduces the rental on capital required of entrepreneurs. Denoting the level of the subsidy by $s$, the condition for continuous (immediate) adjustment to the stock is simply that $\hat{\alpha}_{1}$ be greater (less) than $w+s$. Thus, if the subsidy is large enough, it will accelerate the flow of resources from the old location to the new one. If $s<\alpha_{1}-w$, the subsidy has no effect on the speed at which economic activity changes location. Note that in either case $w$ plus $s$ will be the net wage received by workers. With labor in inelastic supply and capital in perfectly elastic supply, the entire capital subsidy is passed backward to labor. ${ }^{12}$

The model can be made more realistic if it is assumed that there are many industries, with different labor-output ratios, and that $\alpha_{1}$ falls by different amounts in the different industries. In this case, for some size of capital subsidy, the subsidy will push some industries over the boundary between

\footnotetext{
${ }^{12}$ Of course, if the subsidy is raised by taxes on labor, the effect of the subsidy on the net wage is nil. It remains true, however, that $w+s$ is the critical value of $\alpha_{1}$.
} 
continuous adjustment and immediate adjustment. Note that even in this case, whatever effect the capital subsidy may have will be realized immediately. Once the initial shock has taken place, only a change in the subsidy level can move a given industry from a smooth adjustment path to immediate adjustment.

\section{II.B. A Model with Substitution}

Some of the knife-edge properties of the model discussed above can be removed by assuming that the production function, while still $H D 1$, is also twice differentiable and strictly concave in each argument. In addition, denoting the production function as $Q_{i}=f\left(K_{i}, N_{i}\right)$, assume that $f\left(0, N_{i}\right)=$ $f\left(K_{i}, 0\right)=0$.

Because production is $H D 1$ and all markets are perfectly competitive, the equilibrium can be characterized by looking at the economy as a whole. The total capital stock must satisfy:

$$
r=\frac{\partial f}{\partial K}\left(K_{3}, \bar{N}\right)
$$

The wage is determined (at the level of $K_{3}$ that solves (2)) by

$$
w=\left(Q_{3}-r K_{3}\right) / \bar{N}=\frac{\partial f}{\partial N}\left(K_{3}, \bar{N}\right) .
$$

Given an arbitrary distribution of population, $N_{1}=N^{*} ; N_{2}=\bar{N}-N^{*}$, Eqs. (2) and (3) can be used to solve for the amount of capital, and hence output at each location, using the fact that $K_{i} / N_{i}=K_{3} / \bar{N}$ in equilibrium. Again, payments to labor can be viewed as pure rents (although with production $H D l$ the wage is also equal to the value of the marginal product of labor) and the constraints that determine output in the economy are the exogenously given production function, the level of $r$, and the level of $\bar{N}$.

Now consider a shock analogous to that considered in the fixed-coefficient model. Suppose that the production function in location 1 is changed such that the marginal product of labor is reduced at every capital-labor ratio. ${ }^{13}$ Again, the new equilibrium will be one in which all production takes place in location 2, and total output is just equal to the level attained before the shock. In this model, however, the path of adjustment will combine the two polar forms that were possible in the fixed-coefficient model: There will be an immediate flow of resources to location 2 at the time of the shock, followed by an asymptotic approach to the new equilibrium as the capital stock in location 1 wears out.

\footnotetext{
${ }^{13}$ For example, if in the initial equilibrium the production functions in the two locations are identical, the shock could take the form of multiplying the production function in location 1 by some number less than one.
} 
Establishment of these results is straightforward once it is recognized that the market wage will be unchanged by the shock. That the market wage must be constant follows directly from the fact that none of the constraints or opportunities in location 2 have changed $-r$ is fixed, the output price is fixed, and, given that the production function is $H D 1$, both the wage and the capital-labor ratio will continue to be those implied by Eq. (3). This, in turn, implies that at the moment the shock occurs,

$$
w=\frac{\partial f_{1}}{\partial N}\left(K_{1}^{0}, N_{1}\right)=\frac{\partial f}{\partial N}\left(K_{2}, N_{2}\right),
$$

where $K_{1}^{0}$ is the quantity of capital employed at location 1 in the initial equilibrium. Because the shock itself reduces the marginal product of labor at every level of $K_{1} / N_{1}$, and because the marginal product of labor is increasing in $K_{i} / N_{i}$, (4) implies that

$$
K_{1}^{0} / \hat{N}_{1}>K_{2} / N_{2}=K_{i}^{0} / N_{i}^{0},
$$

where $\hat{N}_{1}$ is the value of $N_{1}$ that solves (4). Achievement of inequality (5) requires a flow of labor from location 1 to location 2 immediately the shock occurs. After the initial flow, the capital-labor ratios that solve (4) will continue to hold, and denoting time as $t$ and defining $t=0$ at the instant of the shock,

$$
N_{1}(t)=\hat{N}_{1} e^{-\delta t}
$$

That there will never be investment in location 1 is obvious. At the location 1 ratio of $K$ to $N$, the marginal product of capital in location 1 is always less than $r$. Owners of capital in location 1 absorb a capital loss.

Now consider the effect of an investment subsidy that is put in place at the time of the shock. The subsidy will induce a level of $K_{2} / N_{2}$ that is greater than $K_{i}^{0} / N_{i}^{0}$, implying a higher wage than in the no-subsidy case, and thus also implying a larger initial outflow of labor in order for (4) to hold at the higher wage. The effect of the subsidy will be qualitatively similar if the subsidy is put in place after the shock - the subsidy will induce a one-time outflow of labor from location 1 in order to equalize wages at the higher $K / N$ ratio in location $2 .^{14}$ As in the case of the fixed-coefficient model, any effect that the subsidy has in accelerating the interlocational flow of resources will he "one-shot." After the initial adjustment to the

\footnotetext{
${ }^{14}$ If the subsidy was in effect before the shock, the capital stock would have been larger in both places, (2) would have had to hold with $r-s$ replacing $r$, and everything would be qualitatively similar to the case where there was no subsidy.
} 
subsidy, labor will flow from location 1 to location 2 as capital wears out in location $1 .{ }^{15}$

\section{II.C. A Richer Model-Substitution and a Fixed Factor}

In both of the models discussed in this section, there is some theoretical confirmation of the hypothesis that investment subsidies will increase the flow of resources from declining areas to growing ones. ${ }^{16}$ However, both models have the somewhat distressing implication that the ultimate equilibrium will be one in which all production takes place in the favored location. If ever there was an assertion upon which one might predict that Senators Goldwater and Moynihan would agree, it is that this would be an undesirable and implausible state of affairs. The models presented above consider an extreme case-they are designed to provide maximum scope for general investment subsidies to affect interlocational flows of resources, as well as to provide some intuition on how such flows would occur in the presence of an incompletely durable capital stock. The remainder of this section is devoted to construction and analysis of a model that has implications that I take to be more plausible. First, the initial allocation of labor to locations is not arbitrary. Second, a shock that adversely affects production in location 1 will lead to a finite outflow of resources (i.e., the new equilibrium will involve production in both places). Third, a negative shock will reduce equilibrium wages and output in the economy as a whole. As we shall see, the interlocational effects of investment subsidies in this model are quite different from the effects in the simpler models discussed above.

The model developed in this section takes as its starting place the model of Section II.B, but assumes the following technology:

$$
Q_{i}=f_{i}\left(K_{i}, N_{i}, L_{i}\right)=g\left(K_{i}, N_{i}\right) h_{i}\left(L_{i}\right) \quad(i=1,2),
$$

where $L_{i}$ is land in location $i$, and is fixed in quantity. $f(\cdot)$ is $H D 1$. The function $g(\cdot)$ is strictly concave and homothetic, $\left(\partial^{2} g / \partial N_{i} \partial K_{i}\right)>0$, and $g(0, N)=g(K, 0)=0$.

Without loss of generality, assume that in the initial equilibrium, $h_{1}=h_{2}$ $=h$ and $L_{1}=L_{2}=$ one. ${ }^{17}$ Competitive equilibrium requires that in both

\footnotetext{
${ }^{15}$ Indeed, the continuous rate of labor migration will be lower in the subsidy case, because the capital-labor ratio in location 1 that solves (4) will be higher, implying that less labor is "liberated" per unit of capital that depreciates.

${ }^{16}$ Note, however, that in both cases the effect is on the initial flow, and that the effect on the continuous flow after initial adjustment is either nil or in the direction of reducing the rate of flow.

${ }^{17}$ If we think of locations 1 and 2 as the North and South, respectively, the "initial" state of the world might be characterized as one in which $h_{1}>h_{2}$, but because we are primarily concerned with effects of changes in $h$ from initial equilibria, the details of the initial equilibrium are unimportant.
} 
locations,

$$
\begin{aligned}
& r=h_{i} \frac{\partial g}{\partial K}\left(K_{i}^{0}, N_{i}^{0}\right)(i=1,2), \\
& w=h_{i} \frac{\partial g}{\partial N}\left(K_{i}^{0}, N_{i}^{0}\right)(i=1,2), \\
& R_{i}=g_{i}\left(K_{i}^{0}, N_{i}^{0}\right) \frac{\partial h_{i}}{\partial L} \quad(i=1,2),
\end{aligned}
$$

where $R$ is the rent per unit of land. Note that in this model the values of $K_{i}$ and $N_{i}$ are determined endogenously. Given the values of $L_{i}$, the concavity of the function $g(\cdot)$ implies unique equilibrium quantities of labor and capital at each location. Now suppose that $h_{1}$ falls. The new equilibrium (denoted by the superscript ${ }^{*}$ ) will have the following properties:

$$
\begin{aligned}
K_{1}^{*} / N_{1}^{*} & =K_{2}^{*} / N_{2}^{*} \equiv k^{*}, \\
w^{*} & <w^{0}, \\
k^{*} & <k^{0} \equiv K_{i}^{0} / N_{i}^{0} \quad(i=1,2) .
\end{aligned}
$$

Proof. Homotheticity of $g(\cdot)$ implies that equilibrium capital-labor ratios be equal in all locations where production takes place under competitive conditions. The concavity of $g(\cdot)$, combined with the Inada conditions, assure that at some nonzero level of $K_{1}$ and $N_{1}$ the marginal products of capital and labor in location 1 will equal those in location 2 at any common $K_{i} / N_{i}$ ratio $k$. This establishes (11). Equation (12) can be established by noting first that (11) and the fact that $h_{1}$ has fallen imply that $N_{1}^{*}<N_{1}^{0}$. This, in turn, implies $N_{2}^{*}>N_{2}^{0}$ and hence an increase in the marginal product of capital in location 2 at all values of $K_{2}$. Thus, with $r$ fixed, $K_{2}^{*}>K_{2}^{0}$. The two inequalities in the previous sentence in turn imply (using Eq. 10)) that $R_{2}^{*}>R_{2}^{0}$. Equation (12) follows directly from the fact that $r$ is constant, $R_{2}$ has risen, and $f(\cdot)$ is $H D 1$. Finally, (12) and homotheticity directly imply (13).

The fact that wages must fall in response to a reduction in productivity at one location is not surprising. In contrast to the models presented earlier in this section, the fall in $h_{1}$ leads to a permanent contraction of the economy's production set. There is a permanent reduction in both wage and output. In the other models, with all factors perfectly mobile, a loss in output induced by a reduction in productivity at one location could be replaced by moving the factors. The long-run endowment was unchanged.

There is another important difference between this model and those presented earlier. In the earlier models, the wage stayed constant during the 
process of adjustment to the new equilibrium. In this model, the wage falls immediately when the shock occurs, and then falls continuously until the new equilibrium is reached. ${ }^{18}$ While I would not want to push the point too hard, the results from this model are roughly consistent with the economy's response to the energy price shocks of the 1970s. An immediate loss of output (and fall in real wages) is followed by a migration of resources to locations that gained a comparative advantage in production. Throughout the process, real wages have continued to fall (at least relative to trend), and, at least as found by Baily [1], the effective capital labor ratio has fallen relative to trend. ${ }^{19}$

Capital subsidies in this model have two effects. First, analogous to the other models, a capital subsidy that takes effect at the time of the shock (or after the shock but before the new equilibrium is reached) accelerates the flow of labor from location 1 to location 2, increasing the capital-labor ratio in both locations. Thus, the capital subsidy accelerates the flow of resources towards location 2 . On the other hand, the capital subsidy increases the equilibrium level of capital and output in both locations. Because the rate at which capital depreciates in location 1 is constant, the new equilibrium level of capital and output in location 1 is reached sooner when there is a subsidy. In short, although the outflow of resources is accelerated by a general capital subsidy, the total magnitude of the outflow is reduced. It is this finding that prompted my earlier observation that general capital subsidies will be at worst a mixed curse from the perspective of declining locations. ${ }^{20}$

\section{LOCATIONAL DIFFERENCES IN THE COST OF CAPITAL}

The analysis of capital subsidies in the preceding section was undertaken under the assumption that the net cost of new capital was equal in all locations. Given that there is considerable variation in state and local tax

\footnotetext{
${ }^{18}$ The statement is proved as follows. Immediately after the shock, temporary equilibrium in the labor market implies $k_{1}>k^{*}>k_{2}$. The only way that the required increase in $k_{2}$ can occur is for $w$ to fall.

${ }^{19}$ Among the many reasons why the point should not be pushed too hard is that Baily's argument requires that the existing capital stock be rendered obsolescent by the increase in energy prices. In my model, capital is capital, whether old or new. Among the reasons why the point is worth pushing at all is that differences in energy use in different locations imply that production in some locations will be put at a relative disadvantage by an increase in energy prices. Investigation of the effects of changes in relative productivity is what the model presented here is all about.

${ }^{20}$ The discerning reader will note that the above result is stated in terms of capital, not labor Whether employment in location 1 will be higher with a capital subsidy depends on the details of the production function. If the function $g(\cdot)$ is Cobb-Douglas, the allocation of labor between locations will be the same at any net rental cost of capital
} 
rates on capital income, this assumption is not realistic when applied to the current U.S. tax structure. Moreover, because of the way that federal and lower level taxes interact, changes in the federal tax rules will in general have differential effects in locations that have different tax rules of their own. Thus, both initial equilibria and new equilibria that arise from changes in federal tax policy will be more complicated than those considered in the aggregate models of Section II.

Before proceeding, it is important to distinguish between the effect of different state (local) tax rules on initial equilibria and the effect of such rules on the way in which changes in federal tax rules change equilibria. In the context of the model presented in Section II.C, suppose that location $a$ has a higher tax rate (lower subsidy rate) applying to capital than does location $b$. Equilibrium requires that $k_{a}$ be less than $k_{b}$, and that more labor be employed at $b$ than would be the case if both locations taxed (subsidized) at the same rate as $a$. Now suppose that the federal government reduces its tax rate (raises its subsidy rate). Given that state and local taxes are deductible from federal taxes, if location $b$ has a lower tax rate than location $a$, the percentage reduction in the gross tax rate facing capitalists in location $a$ is smaller than in location $b$, widening the percentage difference in the cost of capital between the two locations. Thus a change in national tax policy can affect locational incentives even if equilibrium between oncegrowing and once-declining regions has been attained.

The remainder of this discussion will consider precisely this type of case -it is assumed that resources are allocated such that full adjustment has been made with respect to any intrinsic locational advantages and disadvantages. The focus will be on how differences in state tax policy affect the nature of such equilibria and adjustment to new equilibria in response to changes in federal tax policy. Because it is true on average (although not for all states) that states in parts of the country that are growing relatively slowly have relatively high statutory tax rates on capital income, consideration of the interaction between state level tax rates and federal tax rules is relevant in a discussion of the effect of federal tax policy on differential growth rates.

\section{III.A. Incentive Effects of Corporate Income Tax Rules}

Analysis of the interactions between local and federal tax rules requires a model of investment demand. The model used here will be the familiar neoclassical formulation, following from the work of Jorgenson [12] and Hall and Jorgenson [11]. In models of this type, corporations (or, more properly, taxpayers facing a marginal tax rate $\gamma$ ) invest in physical assets that have an exponential depreciation rate $\delta$ until the point where a dollar's 
worth of such an asset yields a dollar's worth of discounted returns. Thus,

$$
\begin{aligned}
1= & \int_{0}^{\infty}(1-\gamma) c e^{-(\delta+\bar{r}-\pi) s} d s \\
& +\int_{0}^{\infty} \gamma \delta^{*} e^{-(\delta+\bar{r}) s} d s-(1-\gamma) \int_{0}^{\infty} \tau e^{-(\delta+\bar{r}-\pi) s} d s+k, \\
c(\delta)= & \frac{(\delta+\bar{r}-\pi)\left[\left(\delta^{*}+\bar{r}\right)(1-k)-\gamma \delta^{*}\right]}{(1-\gamma)\left(\delta^{*}+\bar{r}\right)}+\tau,
\end{aligned}
$$

where $k$ is the rate of investment tax credit, $\tau$ is the property tax rate, $c$ is the gross marginal value product of a dollar's worth of the asset, $\pi$ is the inflation rate, $\delta^{*}$ is the rate of depreciation allowed for tax purposes, and $\bar{r}$ is the rate at which the investor discounts future flows of income. As will become apparent later on, $\bar{r}$ depends on both the mix of equity and debt in the finance of the asset and the risk premium demanded by investor. Throughout this discussion, $\gamma$ will be defined as $[1-(1-m)(1-l)]$, where $l$ and $m$ are, respectively, the applicable state and federal marginal tax rates. ${ }^{21}$

As pointed out by Stiglitz [22], if inflation is zero, there is no investment tax credit, tax depreciation equals economic depreciation, and investors discount at the after-tax interest rate $(1-\gamma) i,(15)$ reduces to

$$
c(\delta)=\delta+i+\tau \text {. }
$$

This is precisely the condition that would obtain if there were no corporate tax at all, implying that in this most well-behaved case the corporate income tax has no effect on investment in and of itself. Of course, the market interest rate $i$ may well be affected by other elements of the tax system.

For the remainder of this discussion $I$ assume that $\tau$ is zero. This assumption is made largely for analytical convenience, but it can be at least partially justified by the fact that in the presence of widespread tax abatement programs and the traditional ability of firms to negotiate tax rates with local assessors, the property tax on new investments (all that are

\footnotetext{
${ }^{21}$ Throughout this paper, state and local corporate income taxes are treated as if they are levied on net corporate income attributable to a corporation's operations in a given state or locality. Two recent papers by McLure [13, 14] make the point that the taxable income of corporations doing business in more than one state is typically allocated across states by means of a formula that uses a given state's share of the corporation's national payroll, sales, and property. Thus, state corporate taxes levied on such firms will fall in part on the elements in the formula and in part on net income. The analysis in the text is only valid to the extent that state taxes fall on net income, and the effects of revising the analysis to deal explicitly with the issues raised by the details of state corporate income taxation are not obvious. The issue merits further study, but is not dealt with here.
} 
being considered here) may approximate a benefit tax. If so, it, like wages, is just a payment to other factors of production and should not appear in the cost of capital equation. ${ }^{22}$

In a risk-free world, $(1-\gamma) i$ is the discount rate used in (14), because investors are free to borrow and lend at that rate. ${ }^{23}$ Assuming such a world, consider the effect of differences in $\gamma$ on an investment in a new structure, an asset for which no investment tax credit is allowed.

$$
\frac{\partial c}{\partial \gamma}=\frac{\left(\delta^{*}+i\right) i\left(\delta-\delta^{*}-\pi\right)}{\left(\delta^{*}+(1-\gamma) i\right)^{2}}
$$

(17) is negative if $\left(\delta-\delta^{*}-\pi\right)<0$, a condition that is in no danger of being violated. In short, the higher the tax rate, the lower the equilibrium level of the marginal product of capital. Assuming that capital exhibits diminishing marginal product, this implies that the higher the tax rate the greater will be the equilibrium stock of such capital. Two important assumptions are implicit in (17). First, it is assumed that the nominal interest rate is unchanged by the increased investment demand induced by the higher tax rate. Given that corporate capital is only one of many sectors that attract savings, one would expect the supply of funds to the sector to be quite elastic, but not perfectly so. As long as the supply is not perfectly inelastic, however, the equilibrium marginal product of capital will fall. Second, it is assumed that changes in the corporate tax rate also do not have any direct effect on the nominal interest rate. ${ }^{24}$

\footnotetext{
${ }^{22}$ According to Wolkoff [25] 31 states have formal tax abatement programs. In some cases, no doubt, the property tax winds up being a tax; in others, it is an investment incentive. See Fischel [8] for an elaboration of the argument that the property tax can be seen as a benefit tax.

${ }^{23}$ Many authors have performed analyses of the type used to derive (14) and employed a discount rate $\bar{r}=(1-b) r_{e}+b(1-\gamma) i$, where $b$ is the fraction of the investment financed by debt, and $r_{e}$ is the gross rate of return demanded by equity holders. In a risk-free world, there is no reason for $b$ to be less than unity, because there is no bankruptcy risk. (This argument ignores the possibility that high-bracket taxpayers will be willing to pay a premium for holding equities.)

${ }^{24}$ Because there is no obvious mechanism that would lead to such an effect, the assumption does not appear to be very strong. I make it explicit because other authors have implicitly assumed that the nominal interest rate will respond to inflation according to what Bradford and Fullerton have called "modified Fisher's Law," $i-i_{0}+\pi /(1-\gamma)$, where $i_{0}$ is a fixed "real" rate of interest. This expression is meant to describe the response of nominal interest rates to inflation (and overstates the response through most of 1981). If one mechanically substitutes it into (14) and (15), however, nominal interest rates will "respond" to the corporate tax rate in a way that reverses the inequality in (17).
} 
How can it be that raising the tax rate will stimulate capital formation? Both Eisner [7] and Hall and Jorgenson [11] have shown that in the presence of accelerated depreciation and inflation, the cost of capital could fall as the tax rate rose. The assumption of debt finance increases the effect, because with debt finance the tax has no effect even in the absence of inflation and accelerated depreciation. ${ }^{25}$ More intuitively, in the presence of accelerated depreciation and inflation it can be shown that the tax base generated by a dollar's worth of debt-financed capital is negative, implying that increasing the tax rate acts as a subsidy. ${ }^{26}$ The tax base $(B)$ (per time period) can be expressed as:

$$
B=c-\delta^{\prime}-i,
$$

where $\delta^{\prime}$ is the rate of depreciation allowed for tax purposes on a dollar's worth of capital and is given by:

$$
\delta^{\prime}={\frac{\delta^{*}(\delta+\bar{r}-\pi)}{\delta^{*}+\bar{r}}}^{27}
$$

When $\bar{r}=(1-\gamma) i$ and there is no investment tax credit, substituting (19) and (18) into (15) yields

$$
B=\frac{i\left(\delta-\delta^{*}-\pi\right)}{\delta^{*}+(1-\gamma) i} .
$$

\footnotetext{
${ }^{25}$ The preceding does not mean that inflation by itself need act as an investment stimulus. The well-documented negative effect of inflation on the real value of depreciation deductions allowed on historical costs increases the cost of capital, and, of course, both inflation and the fact that nominal capital gains are taxed at the personal level will tend to increase interest rates. also reducing investment. (But see White [24] for evidence that (at least through the fall of 1981) in the past decade, nominal interest rates had not risen nearly enough to maintain after-tax borrowing costs for corporations. Indeed, the reduction in real after-tax interest rates more than offset the negative effects that inflation had had through reducing the value of depreciation deductions.) All that is being claimed here is given inflation and debt-finance. an increase in the corporate tax rate will act as an investment stimulus at the margin.

${ }^{26}$ Bradford and Fullerton have argued [3] that the use of $(1-\gamma)$ as a discount rate does not imply that debt-finance is used, but rather merely implies that the corporation has taken advantage of all opportunities for arbitrage between debt and equity at the interest rate $(1-\gamma) i$. Because the mechanism for taking advantage of such opportunities is in fact to engage in debt-finance, elucidation of the model by examining the tax base under the assumption of such finance seems to be justified.

${ }^{27}$ See Gordon [9] for a derivation.
} 
In the presence of an investment tax credit at rate $k,(20)$ becomes

$$
B=\frac{(1-\gamma) i\left(\delta-\delta^{*}-\pi\right)-k(\delta+(1-\gamma) i-\pi)\left((1-\gamma) i+\gamma \delta^{*}\right)}{\left(\delta^{*}+(1-\gamma) i\right)(1-\gamma)}
$$

Again, the presence of either accelerated depreciation or positive inflation with $\delta=\delta^{*}$ assures that (20) and (21) are negative. This implies that the greater the tax rate, the greater the rate of subsidy. To the extent that the slower-growing regions have higher tax rates on corporate income, they subsidize capital more, and, in the context of the model presented in Section II.C, this implies that their equilibrium levels of both capital and employment will be increased. Of course, (20) and (21) also imply that if the tax were fully refundable it would raise negative revenue. Moreover, a state or locality seeking to increase its subsidy to capital by raising the tax in amount $\Delta l$ would lose revenue of $\Delta l B$ per dollar of new investment but would increase the effective subsidy rate to corporations by only ( 1 $m) \Delta l B$. Just as deductibility of local taxes is a subsidy to local taxation, deductibility of what is in this case a local subsidy is a tax on local subsidies.

The fact that the corporate income tax raises revenue implies that the risk-free competitive world implicit in the model used above is not the world we live in. This does not mean that the results derived above are without value. They imply that a risk-free corporate investment is subsidized by the tax system, and that the subsidy is greater the higher the statutory tax rate. This point is especially important in light of a recent paper by Gordon [10]. Gordon's work implies that if the tax on a risk-free investment is zero, the corporate income tax (more exactly, the entire complex of taxes on capital income) falls entirely on risk-premia and economic profits, and both raises revenue and is nondistorting. ${ }^{28}$ Additionally, Gordon finds that for plausible parameter values essentially all of the real return to capital can be attributed to the risk premium, implying that essentially all of the revenue raised has no incentive effects.

Formal incorporation of Gordon's analysis into this discussion is a major undertaking, reserved for another paper. Informally, however, Gordon's

\footnotetext{
${ }^{28}$ That taxes on economic profits are nondistorting is well known. The reason that taxes on risk-premia can be nondistorting is that the tax reduces both the rate of return and the covariance of the return on a given investment with the return on the market portfolio. Thus, the government bears some risk, and charges the market price for the risk that it bears, leaving no net effect on risk-taking. A similar point has also been made by Mossin [15] and Stiglitz [21]. Gordon [10] shows that these results do not depend on the relatively restrictive assumptions embodied in the capital asset pricing model.
} 
results show promise in illuminating a finding that has puzzled many economists. To date, the great majority of studies that have examined the effect of tax differences on industrial location have found no effect, and when effects have been found they have been small. ${ }^{29}$ Similarly, the role of the cost of capital in time series investment equations also appears to be very small in comparison to that of short-run changes in output. ${ }^{30}$ If the return on investments is almost entirely attributable to the risk premium, and if the tax on the risk premium has no incentive effects, then the effects of tax policy are necessarily small, as taxes have incentive effects only as they influence the risk-free rate of return, which is a small (in Gordon's case, zero) portion of the total return.

\section{III.B. Interactions between Federal and State (Local) Income Tax Rules}

The main elements of the federal corporate income tax are three:

(1) The rate schedule, especially the maximum marginal rate.

(2) The depreciation rules allowed for tax purposes.

(3) The investment tax credit.

Changes in any of these three elements will have different effects on investment in different locations, depending on the degree of integration between the applicable state and local rules and the federal rules, and, through deductibility, on the combined state and local tax rate applicable in the different locations. The most straightforward case to analyze obtains when lower levels of government define taxable income under the same rules that the federal government uses. Thus, the analysis of changes in depreciation provisions that follows applies only to states and localities that use the federal rules. ${ }^{31}$

\footnotetext{
${ }^{29}$ See Wolkoff [25] for a review of this literature as well as support for finding that there is little or no effect.

${ }^{30}$ See Clark [6] for a careful comparison of different models that leads to the result stated in the text. Chirinko and Eisener [4], in a review of investment equations used in a large number of macroeconomic models, conclude that the effect of capital taxes is at best uncertain.

${ }^{31}$ According to the Citizens for Tax Justice, 25 states currently use the federal rules. A recent article in the New York Times implies that 19 states are considering adopting rules of their own, and 14 states that currently have their own rules are considering adopting the federal nules. If states use their own definitions of the tax base, then changes in federal depreciation rules that stimulate investment will increase investment demand in other states that use the federal rules more than they will increase demand in the states that use less generous rules. The differential effect will clearly favor the states using federal rules, although the fiscal position of governments in those states (because the federal rules reduce the tax base) may be harmed. The locationally differential effects of changes in the investment tax credit or changes in the federal tax rate are essentially independent of state and local level depreciation rules; they are functions of the tax rates obtaining at the lower levels of government.
} 


\section{Differential Effects under Pure Equity Finance}

In order to investigate interactions between federal and local rules when the tax on a risk-free investment is positive, consider (15) in the case of $100 \%$ equity finance. Here, $\bar{r}$ is independent of $\gamma$, and higher tax rates imply lower equilibrium levels of the capital stock. ${ }^{32}$ For each of the three possible changes in federal tax rules, compute the percentage change in $c$ due to a change in federal tax rules and then differentiate the result with respect to the local tax rate. If the percentage change in $c$ is negative (as it is for a national investment stimulus) then, assuming constant elasticity of demand for capital services in different locations, higher-tax locations will be differentially favored (harmed) by the investment stimulus in question as $\partial / \partial l$ (percentage change in $c$ ) is negative (positive). The relevant manipulations yield:

$$
\begin{aligned}
\frac{\partial}{\partial l}\left(\frac{1}{c} \frac{\partial c}{\partial k}\right) & =\frac{-z(1-m)}{(1-k-\gamma z)^{2}}, \\
\frac{\partial}{\partial l}\left(\frac{1}{c} \frac{\partial c}{\partial z}\right) & =\frac{(1-m)(k-1)}{(1-k-\gamma z)^{2}} \\
\frac{\partial}{\partial l}\left(\frac{1}{c} \frac{\partial c}{\partial m}\right) & =\frac{-\gamma z(1-k-z)}{(1-\gamma)(1-k-\gamma z)^{2}},
\end{aligned}
$$

where $z$ is the present value of depreciation deductions and is equal to $\delta^{*} /\left(\delta^{*}+\bar{r}\right)$. Equations (22) and (23) are clearly negative, implying that increasing the investment tax credit or the present value of depreciation allowances differentially favors regions that have higher own tax rates. Equation (24) is negative if $1-k-z$ is positive, a condition that always obtains for new structures and holds for all new equipment if the discount rate is 0.075 or greater, and for all equipment other than autos and trucks if the discount rate exceeds 0.044 . Note that $\partial c / \partial m$ is positive, implying that if (24) is negative, reductions in federal corporate income tax rates tend to reduce the equilibrium share of the capital stock going to higher-tax regions. It is interesting to note that the methods of investment stimulus chosen in the 1981 tax law tend to differentially favor investment in areas that have higher local tax rates.

\section{Differential Effects When the Tax Base Is Negative}

Earlier in this discussion it was shown that for risk-free investments the corporate income tax base is negative. Under these conditions, it is easy to

\footnotetext{
${ }^{32}$ An assumption of mixed finance would yield qualitatively similar results provided that the derivative of (15) with respect to $\gamma$ were positive.
} 
show that if depreciation allowances are liberalized, the higher tax rate states (that is, higher subsidy rate) are differentially favored. Conversely, an increase in the federal statutory tax rate (which would act as an investment stimulus) would have the most effect in relatively low tax rate states, as it would reduce the net percentage difference in tax (i.e., subsidy) rates among states.

\section{IMPLICATIONS}

The strongest conclusion that can be drawn from the preceding analyses is a negative one: it is not at all obvious that national investment stimuli will tend to favor growing regions at the expense of declining ones. ${ }^{33}$ The analysis in Section II of the paper implies that unless one believes that the equilibrium size of declining regions is vanishingly small, investment stimuli will tend to reduce the ultimate outflow of resources from such regions. The analysis in Section III implies that some national stimuli will tend to provide differentially favorable incentives to investment in higher tax areas, while others will favor lower tax areas. (Note that this last result does not depend on the admittedly disturbing finding that the tax on a risk-free investment is negative.) Thus, the effects of stimuli will be mixed, and the form of the stimulus chosen will matter.

A somewhat weaker implication of the analysis is that states that are trying to recoup fiscal losses caused by the 1981 Tax Act would be well-advised to consider raising their corporate income tax rate rather than changing their depreciation rules to something less liberal than the new federal rules. Failing to employ the new federal rules will act as clear disincentive to new investment (relative to states that go along with the new rules) while raising the corporate tax rate may act as an incentive by itself, will surely enhance the incentive effects of the new federal rules, and, in any event, will raise a good deal of revenue from inframarginal investments already in place.

Because the models analyzed in this paper distinguish among locations only on such broad criteria as tax rates and whether activity is growing or declining, potentially important issues related to the differential impact of investment incentives on central cities vs. suburbs have not been addressed directly. In order to redress this, the models of Section II would have to be revised to take account of the problem that arises when existing urban structures are ill-suited to modern equipment. At the same time, it would be fruitful to model changes in energy costs explicitly, to see how they would affect areas that have old structures relative to areas that have vacant land. However, it should be emphasized that if the problems facing central cities in the north can largely be attributed to an outmoded stock of structures,

\footnotetext{
${ }^{33}$ See Schwab [19] for an explicit model of regional competition that leads to a similar result.
} 
failing to promote investment nationwide will do nothing to address these problems, while promoting investment nationwide will still increase the equilibrium size of the cities involved. Calculation of the magnitude of this effect, however, awaits a more detailed theoretical apparatus as well as considerable empirical work.

This paper began with the remark that regional and urban concerns have become live issues in the making of federal tax policy. The analysis in this paper leads me to the tentative conclusion that these issues have received more attention than they deserve. To the extent that investment stimuli are effective, they will increase the equilibrium size of declining areas, and thus they may be desirable from the perspective of residents (especially landowners) in those areas. Moreover, there is good reason to believe that the incentive effects of national policies are small in any event. If they are, there is no problem; if they are not, their positive effects will be felt in old places as well as new ones.

\section{REFERENCES}

1. M. N. Baily, Productivity and the services of capital and labor, "Brookings Papers on Economic Activity," No. 1, The Brookings Institution, Washington, D.C. (1981).

2. D. F. Bradford, Tax neutrality and the investment tax credit, in "The Economics of Taxation" (Aaron and Boskin, Eds.), The Brookings Institution, Washington, D.C. (1980).

3. D. F. Bradford and D. Fullerton, "Pitfalls in the Construction of Effective Tax Rates," NBER Working Paper No. 688, NBER, Cambridge, Mass. (June, 1981).

4. R. S. Chirinko and R. Eisner, "The Effects of Tax Policies in the Investment Equations of Macroeconometric Models: Full Model Simulation," Office of Tax Analysis Paper No. 46, U.S. Treasury, Washington, D.C. (January 1981).

5. Citizens for Tax Justice, "The Impact of Recent Changes in Federal Depreciation Tax Rules on State Revenues," Washington, D.C. (August 7, 1981).

6. P. Clark, Investment in the 1970's: Theory, performance, and prediction, "Brookings Papers on Economic Activity," No. 2, The Brookings Institution, Washington, D.C. (1979).

7. R. Eisner, What went wrong? J. Pol. Econ., 629-641 (May/June, 1971).

8. W. Fischel, Fiscal and environmental considerations in the location of firms in suburban communities," in "Studies in Fiscal Zoning and Land Use Controls," (Mills and Oates, Eds.), Heath, Lexington, Mass. (1975).

9. R. H. Gordon, "Inflation, Taxation, and Corporate Behavior," NBER Working Paper No. 588, NBER, Cambridgc, Mass. (Dccember, 1980).

10. R. H. Gordon, "Taxation of Corporate Capital Income: Tax Revenues vs. Tax Distortions," mimeo (1981).

11. R. Hall and D. Jorgenson, Tax policy and investment behavior, Amer. Econ. Rev., 57 , 391-414 (June, 1967).

12. D. Jorgenson, Capital theory and investment behavior, Amer. Econ. Rev., 53, 247-259 (May 1963).

13. C. McLure, Jr., The state corporate income tax lamb in wolves' clothing, in "The Economics of Taxation," (Aaron and Boskin, Eds.), The Brookings Institution, Washington, D.C. (1980).

14. C. McLure, Jr., "The Elusive Incidence of the Corporate Income Tax: The State Case," NBER Working Paper No. 616, NBER, New York (January, 1981). 
15. J. Mossin, Taxation and risk-taking: An expected utility approach, Economica, 35, 74-82 (1968).

16. Northeast-Midwest Institute, "A Review of the Office of Management and Budget's 'Regional Analysis of the President's Economic Recovery Program'" (April 24, 1981).

17. G. Peterson, "The Impact of Federal Fiscal Policies on Urban Economic Development," U.S. Dept. of Commerce, Washington, D.C. (September, 1980).

18. G. Peterson and T. Mueller, "Regional Impact of Federal Tax and Spending Policies," in "Alternatives to Confrontation" (Arnold, Ed.), Heath, Lexington, Mass. (1980).

19. R. M. Schwab, "The Regional Effects of Investment Initiatives," unpublished manuscript, University of Maryland (January, 1982).

20. R. Solow, "Growth Theory: An Exposition," Oxford Univ. Press, New York/London, (1970).

21. J. Stiglitz, Effects of wealth, income, and capital gains taxation on risk taking, $Q . J$. Econ., 83, 262-283 (1969).

22. J. Stiglitz, Taxation, corporation financial policy, and the cost of capital, J. Public Econ., 2, 1-34 (January, 1973).

23. R. Vaughan, "The Urban Impacts of Federal Policies: Vol. 2, Economic Development," The Rand Corporation, Santa Monica, Calif. (June, 1977).

24. M. J. White, "Investment Incentives Under the 1981 Tax Law," mimeo (Nov. 1981).

25. M. J. Wolkoff, "An Analysis of the Use of Tax Abatement Policy to Stimulate Urban Economic Development," Ph.D. dissertation, Public Policy Studies, University of Michigan (1981) 